\title{
Norovirus infections in preterm infants: wide variety of clinical
}

\section{courses}

\author{
Sven Armbrust ${ }^{1}$, Axel Kramer ${ }^{2}$, Dirk Olbertz ${ }^{3}$, Kathrin Zimmermann ${ }^{4}$ and \\ Christoph Fusch*1
}

Address: ${ }^{1}$ Department of Neonatology, University-Children's Hospital, 17475 Greifswald, Germany, ${ }^{2}$ Institute for Hygiene and Environmental Medicine, Ernst Moritz Arndt University Greifswald, 17475 Greifswald, Germany, ${ }^{3}$ Department of Neonatology, Suedstadt Clinic, 18059 Rostock, Germany and ${ }^{4}$ Friedrich Loeffler Institute for Medical Microbiology, Ernst Moritz Arndt University Greifswald, 17475 Greifswald, Germany

Email: Sven Armbrust - sven.armbrust@web.de; Axel Kramer - kramer@uni-greifswald.de; Dirk Olbertz - dirk.olbertz@kliniksued-rostock.de; Kathrin Zimmermann - kazimmer@uni-greifswald.de; Christoph Fusch* - fusch@mcmaster.ca

* Corresponding author

Published: 2 June 2009

BMC Research Notes 2009, 2:96 doi:10.1 186/1756-0500-2-96
Received: 17 October 2008

Accepted: 2 June 2009

This article is available from: http://www.biomedcentral.com/1756-0500/2/96

(C) 2009 Fusch et al; licensee BioMed Central Ltd.

This is an open access article distributed under the terms of the Creative Commons Attribution License (http://creativecommons.org/licenses/by/2.0), which permits unrestricted use, distribution, and reproduction in any medium, provided the original work is properly cited.

\begin{abstract}
Background: Norovirus is an important cause of nonbacterial acute gastroenteritis in all ages. Atypical courses are described. Clinical symptoms are diarrhea, vomiting, nausea, abdominal cramps, fever and malaise. Apart from three recent short reports we describe for the first time an outbreak of norovirus in a tertiary Neonatal Intensive Care Unit.
\end{abstract}

Findings: The typical symptoms of norovirus infection are in part also seen in premature born infants but with a different pattern and a huge variety of clinical courses. Vomiting is not the main symptom of norovirus infection in premature infants but distended abdomen and other symptoms such as apnea, gastric remainders or sepsis like appearance. The course in premature born patients could be explained by an immunocompromised mice model. Extensive hygienic measures were necessary to control the outbreak without closing the Neonatal Intensive Care Unit.

Conclusion: Norovirus infection in premature infants shows an impressive pattern of a wide variety of clinical courses. Only the consequent use of different hygienic pattern can lead to elimination of norovirus.

\section{Background}

Norovirus, belonging to the family of Caliciviridae, is a highly contagious virus and has been found to be one of the most important causes of nonbacterial acute gastroenteritis in all ages in developing as well as in developed countries [1-3]. While most of the outbreaks are known to have a seasonal pattern, sporadic cases of disease throughout the year are described [4,5]. Although outbreaks can occur in a variety of settings, semiclosed communities like hospitals are favoured [6]. Norovirus are transmitted through common sources such as food and water, personto-person contact or airborne via aerosolized vomit whereas an extremely small dose of virus patricles $(3-10)$ already can lead to infection [7-9]. Norovirus can be detected by ELISA as in this report, by RT-PCR or electron microscopy.

A lot of reports and studies about norovirus and its outbreaks exist covering a wide range of different areas and age groups with the few, typical clinical symptoms. Atypi- 
cal courses of the disease are described in immunocompromised patients and persons under severe stress $[10,11]$.

Cause of this outbreak was a mother of a hospitalised preterm baby. She suffered from typical clinical signs of norovirus infection including acute diarrheal illness and was tested positive for norovirus shortly before the onset of clinical symptoms in our patients.

Apart from three recent reports dealing with norovirus outbreaks in premature infants we describe for the first time an outbreak of norovirus infections, its clinical course and control with extensive hygienic measures in a tertiary Neonatal Intensive Care Unit (NICU) affecting 11 infants over a period of two months showing an impressive pattern of a wide variety of clinical courses $[12,13]$.

\section{Case Report \\ Case I}

26 weeks of gestation, $760 \mathrm{~g}$, on nasal CPAP, on day 14 acute severe worsening of the general condition, anemia, increasing oxygen demand, sepsis-like clinical appearance with increasing apnea followed by intubation and ventilation for 7 days, proof of norovirus for three weeks also in tracheal aspirate.

\section{Case 2}

26 weeks of gestation, $820 \mathrm{~g}$, initial clinical course without complications, on day 34 sudden development of tachycardia, restlessness, distended abdomen and worsening of general condition, sepsis-like clinical appearance with tachypnea, thrombocytopenia and anemia, increasing oxygen demand. Proof of norovirus, later also rotaand astrovirus. Child developed necrotizing enterocolitis $2 \mathrm{~B}^{\circ}$ and underwent surgery with left sided hemicolectomy and ileostoma.

\section{Case 3}

29 weeks of gestation, $1150 \mathrm{~g}$, on day 5 acute worsening of the general condition, increasing gastric remainders, vomiting, distended abdomen, proof of norovirus.

\section{Case 4}

25 weeks of gestation, $740 \mathrm{~g}$, increasing oxygen demand, recurrent severe apnea with bradycardia parallel to the detection of norovirus. Recurrent severe infection during a two month period with constant proof of norovirus shedding. No abdominal symptoms.

\section{Case 5}

32 weeks of gestation,
1. twin, $990 \mathrm{~g}$, distended abdomen, on day 21 vomiting and distended abdomen, parenteral nutrition, proof of norovirus

2. twin, $1900 \mathrm{~g}$, distended abdomen, greenish - mucous stool with visible blood, norovirus suspected but not surely proven

\section{Case 6}

29 weeks of gestation, $1170 \mathrm{~g}$, distended abdomen, proof of norovirus

\section{Case 7}

32 weeks of gestation,

1. triplet, $1780 \mathrm{~g}$, on day 7 vomiting and distended abdomen for five days, proof of norovirus.

2. triplet, $1260 \mathrm{~g}$, on day 8 acute worsening of the general condition, green gastric remainder, increasing oxygen demand, increasing apnea and respiratory insufficiency, then mucous stool with visible blood followed by colitis and coecostomy, capillary leak and multi organ failure, death on day 14 . Norovirus not surely proven but proof of rotavirus

3. triplet, $1480 \mathrm{~g}$, on day 11 slight worsening of the general condition with pale marble like skin colour, gastric remainder, distended abdomen, stool with visible blood, no proof of norovirus.

\section{Case 8}

29 weeks of gestation, $1220 \mathrm{~g}$, on day 4 slight gastric remainder with fresh blood, proof of norovirus infection

All different clinical symptoms are summarized in table 1:

\section{Discussion}

Norovirus has not been proven in all our patients but according to the case categories of the German Federal Health Office (Robert - Koch - Institute, Berlin, Germany) norovirus infection can be assumed in an outbreak with similar clinical courses, proof of norovirus and/or with an epidemiological connection [14]. Other similar definitions have been also used in defining norovirus outbreak $[15,16]$. Also the given sensitivity and specificity of ELISA tests can lead to negative results despite the presence of norovirus [17]. The test used at our laboratory was a commercial ELISA test kit (Ridascreen Norwalk like virus, R-Biopharm, Darmstadt, Germany) [18].

Two recent studies question the validity of enzyme immunoassays (ELISA) in norovirus infection and request RTPCR instead [12,13]. It seems true that the currently available methods vary greatly in sensitivity, specificity and 
Table I: Clinical symptoms of all cases

\begin{tabular}{|c|c|c|c|c|c|c|c|c|c|c|c|}
\hline & Case I & Case 2 & Case 3 & Case 4 & Case 5.1 & Case 5.2 & Case 6 & Case 7.1 & Case 7.2 & Case 7.3 & Case 8 \\
\hline Respiratory insufficiency & $x$ & & & & & & & & $x$ & & \\
\hline Apnea/Tachypnea & $x$ & $x$ & & $x$ & & & & & $x$ & & \\
\hline Additional oxygen & $x$ & $x$ & & $x$ & & & & & $x$ & & \\
\hline Sepsis like & $x$ & $x$ & & & & & & & & & \\
\hline Anemia & $x$ & $x$ & & & & & & & & & \\
\hline Thrombocytopenia & & $x$ & & & & & & & & & \\
\hline Tachycardia & & $x$ & & & & & & & & & \\
\hline Gastric Remainders & & & $x$ & & & & & & $x$ & $x$ & $x$ \\
\hline Distended Abdomen & & $x$ & $x$ & & $x$ & $x$ & $x$ & $x$ & & $x$ & \\
\hline NEC/colitis & & $x$ & & & & & & & $x$ & & \\
\hline Vomiting & & & $x$ & & $x$ & & & $x$ & & & \\
\hline Recurrent severe infections & & & & $x$ & & & & & & & \\
\hline Blood stool & & & & & & $x$ & & & $x$ & $x$ & \\
\hline Blood in Gastric Remainders & & & & & & & & & & & $x$ \\
\hline Skin colour & & & & & & & & & & $x$ & \\
\hline Death & & & & & & & & & $x$ & & \\
\hline \multicolumn{12}{|l|}{ Proof of Virus } \\
\hline In stool & $x$ & $x$ & $x$ & $x$ & $x$ & (?) & $x$ & $x$ & (?) & & $x$ \\
\hline In tracheal aspirate & $x$ & $x$ & & & & & & & & & \\
\hline
\end{tabular}

scope for the detection of norovirus [17]. RT-PCR was not available in our study but in a study by Duizer et al. the sensitivity using ELISA increases with sufficient positive samples [19]. In another study by Rabenau et al. which compared ELISA, PCR and transmission electron microscopy it was shown that all three methods are useful [20]. The discrepancies seen can be explained by the different components each method detects. Even though PCR has the highest sensitivity a negative PCR would not necessarily exclude norovirus infection. Having a source with proven norovirus infection plus the typical clinical course in a mother of one of our hospitalised preterm babies and eight positive samples plus a much better sensitivity in our test kit we therefore see the results of our ELISA being sufficient to confirm norovirus outbreak in our patients.
General clinical symptoms of norovirus infection are described as diarrhea, vomiting, nausea, abdominal cramps, fever and malaise, whereas vomiting occurs more frequently in children and diarrhea more typically in adults [14]. The disease typically lasts one to four days, is self-limited and does not cause chronic infection. Shedding of human calicivirus can last for two weeks and younger children tend to shed for a longer period than older children [21]. Viruses can be detected in stool specimens of some children for a longer period without any signs for illness [22].

Looking at the wide variety of clinical courses in our patients it becomes clear that gastrointestinal problems are the leading symptoms also in neonates $(81.8 \%)$. 
According to Kaplan et al. one should always consider norovirus infection in case of explosive vomiting in more than $50 \%$ of the patients, acute diarrhea for a period of 12 to 60 hours with an incubation period of 6 to 48 hours [23]. Given these criteria vomiting occurred in only $27 \%$ of our patients whereas $63 \%$ suffered from distended abdomen. None of our patients suffered from acute diarrhea and apart from abdominal distension only one third showed signs of a lower gastrointestinal tract involvement. A very recent study by Turcios-Ruiz et al. described an outbreak of necrotizing enterocolitis caused by norovirus especially in small premature infants which supports our observation in case 2 and our assumption that case 7.2 suffered also from norovirus infection although the norovirus infection has not been confirmed in this case [24].

During the outbreak all patients of the NICU received a regular screening for norovirus. We found no asymptomatic carriers in our patients.

In general pulmonary symptoms are often the first non specific sign for infection in premature born infants but interestingly these last longer in patients with norovirus infection. Given the immaturity of the immune system of the premature born organism it is surprising that in one case we nearly did not see any signs for infection whereas it is known that the susceptibility of human to norovirus infection is determined by allelic variation in human histo-blood group antigens (HBGA) as described by Huang and others [25]. Proof of norovirus in tracheal aspirate has not been described before (case 1 and 2) and was done in our cases as we initially could not explain the high increase of oxygen demand. Apart from a direct infection of respiratory mucosal cells it might be possible that external contamination could have led to a contamination of respiratory secretions and also microaspiration.

Currently norovirus is divided into 7 genogroups with more than 40 genetic clusters but many aspects of norovirus biology are not well understood [26]. The murine norovirus model system provides the first opportunity to understand the mechanism and pathogenesis of the infection [27]. In this mouse model Karst et al. were able to show that severely immunocompromised mice lacking the signal tranducer and activator of transcription 1 (STAT1) had high levels of virus RNA in all organs examined. Also these mice had histopathological signs of pneumonia and loss of splenic architecture and severe liver inflammation after oral inoculation [27]. Seeing the premature infant as a "naturally" immunocompromised patient this observation might explain the wide variety of clinical courses.
One might only speculate whether a prolonged virus shedding and so related immune reaction may lead to a higher susceptibility to bacterial infection in premature born infants as seen in case 4 or whether it is only expression of an immunocompromised situation with an extended time for recovery.

A couple of problems are pathognomonic for NICUs worldwide: there is rarely a larger space between the incubators. The opening of a heated incubator is similar to an overpressurized chamber and will inevitabely lead to an airborne spread of particles. The frequent visit from parents and relatives and even smaller infants are highly supported to strengthen the bonding between the preterm infant and its family. This all can lead to a persistent and circulating infection especially in a semi-closed community as described earlier [6].

Therefore only the consequent use of different hygienic pattern can lead to elimination of norovirus in such a setting. In our case it was wearing single use coats, gloves and surgical face mask whenever a patient was handled and increased use of norovirus active disinfectants as hand disinfection and on the ward (wiping of floor and surfaces especially around incubators). At the beginning we used a hand disinfectant which was recommend as highly effective on enveloped and non-enveloped viruses although not specifically tested against feline calicivirus (surrogate virus for norovirus) according to the Robert - Koch Institute [28]. Its pharmaceutically active ingredients contain Ethanol $95.0 \mathrm{~g}$ (on $100 \mathrm{~g}$, Sterillium Virugard ${ }^{\mathrm{Tm}}$, Bode Hamburg/Germany). As we could not stop the outbreak herewith we changed to a new, ethanol reduced hand disinfectant: Manorapid Synergy ${ }^{\mathrm{TM}}$ (Antiseptica, Pulheim/ Germany). Its pharmaceutically active ingredients contain 10 g 1-Propanol, 57,6 g Ethanol 96\% with 0,7\% phosphoric acid (on $100 \mathrm{~g}$ ). This disinfectant produced a $\log _{10}$ reduction factor of 2.38 in testing against feline calicivirus compared to other disinfectants with increased ethanol content [29]. For floor disinfection Perform ${ }^{\mathrm{TM}} 1 \%$ (Schülke \& Mayr, Norderstedt/Germany) was used which is an active oxygen based highly effective disinfectant containing $45 \mathrm{~g}$ Pentakalium bis(peroxymonosulfate)bis(sulfate) and has been tested as being effective against feline calicivirus.

All symptomatic patients underwent strict cohortation and care by dedicated nurses, who were not allowed to care for other patients and to leave that area during work. Relatives were not allowed to get into personal contact with their babies or to peform "kangarooing" as long as we could prove shedding of virus. 
With this hygienic management we were able to limit the disease and completely terminate it after two months (case 4).

Finally, although not in our case, it can be necessary to close a ward completely until the virus is eradicated. This "worst case scenario" leads to a loss of proceeds which was calculated by Lopman et al. as 1,01 million \$ per 1000 hospitals beds [30].

\section{Competing interests}

The authors declare that they have no competing interests.

\section{Authors' contributions}

SA planned and carried out the study, collected data and wrote the manuscript. AK planned and carried out all hygienic measures and revised the manuscript critically. DO participated substantially in the design of the study and data collection. KZ carried out the ELISA testing. CF controlled the study and revised the manuscript critically for important intellectual content

All authors read and approved the final manuscript to be submitted to BMC Research Notes.

\section{Acknowledgements}

A specific approval of the Institutional Review Board of the University Hospital Greifswald is not necessary as no research was done on the patients according to the Medical Association's professional code of conduct of Mecklenburg - Vorpommern/Germany. Also written consent from the parents for publication of this study is not necessary according to the Institutional Review Board of the University Hospital Greifswald and the Medical Association's professional code of conduct of Mecklenburg - Vorpommern/Germany as neither personalized data nor picture are published. Oral informed consent was obtained from the parents to collect and publish the data.

\section{References}

I. Jiang X, Graham DY, Wang KN, Estes MK: Norwalk virus genome cloning and characterization. Science 1990, 250:1580-I583.

2. Ike AC, Brockmann SO, Hartelt K, Marschang RE, Contzen M, Oehme RM: Molecular epidemiology of norovirus in outbreaks of gastroenteritis in southwest Germany from 2001 to 2004. J Clin Microbiol 2006, 44(4): I262-I 267.

3. Lopmann B, Vennema H, Kohli E, Pothier P, Sanchez A, Negredo A, Buesa J, Schreier E, Reacher M, Brown D, Gray J, Iturriza M, Gallimore C, Bottiger B, Hedlund KO, Torvén M, von Bonsdorff CH, Maunula L, Poljsak-Prijatelj M, Zimsek J, Reuter G, Szücs G, Melegh B, Svennson $L$, van Duijnhoven $Y$, Koopmans M: Increase in viral gastroenteritis outbreaks in Europe and epidemic spread of new norovirus variant. Lancet 2004, 363:682-688.

4. Piang XL, Honma S, Nakata S, Vesikari T: Human Calicivirus in acute gastroenteritis of young children in the community. J Infect Dis 2000, 181:288-294.

5. Maguire AJ, Green J, Brown DWG, Desselberger U, Gray JJ: Molecular epidemiology of outbreaks of gastroenteritis associated with small round-structured viruses in East Anglia, United Kingdom during the 1996 - 1997 season. J Clin Microbiol 1999, 37:8I-89.

6. Vinjé J, Koopmans PG: Molecular detection and epidemiology of small round-structured virusesin outbreaks of gastroenteritis in the Netherlands. J Infect Dis 1996, 174:610-615.

7. Widdowson MA, Sulka A, Bulens SN, Beard RS, Chaves SS, Hammond R, Salehi ED, Swanson E, Totaro J, Woron R, Mead PS, Bresee JS,
Monroe SS, Glass RI: Norovirus and foodborne disease, United States 1991 - 2000. Emerg Infect Dis 2005, I I:95-102.

8. Koch J, Schneider T, Stark K, Schreier E: Norovirusinfektionen in Deutschland. Bundesgesundheitsbl-Gesundheitsforsch-Gesundheitsschutz 2006, 49:296-309.

9. Becker KM, Moe CL, Southwick KL, MacCormack JN: Transmission of Norwalk virus during football game. Engl J Med 2000, 343: 1223-1 227.

10. Simon A, Schildgen O, Eis-Hübinger M, Hasan C, Bode U, Buderus S, Engelhart $S$, Fleischhack G: Norovirus outbreak in a pediatric oncology unit. Scand J Gastroenterol 2006, 41:693-699.

II. CDC: Outbreak of acute gastroenteritisa associated with Norwalk-like viruses among British military personnel Afghanistan. MMWR 2002, 5 I:477-9.

12. Wiechers C, Bissinger AL, Hamprecht K, Kimmig P, Jahn G, Poets C: Apparently non-specific results found using a norovirus antigen immunoassay for fecal specimens from neonates. J Perinatol 2008, 28:79-8I.

13. Köhler $H$, Jüngert J, Korn $K$ : Norovirus pseudo-outbreak in a neonatal intensive care unit. J Pediatr Gastroenterol Nutr 2008, 46:47I-472.

14. Falldefinitionen des Robert-Koch-Instituts zur Übermittlung von Erkrankungs-oder Todesfällen und Nachweisen von Krankheitserregern. RKI, Berlin; 2004:102-103.

15. Lopman BA, Reacher MH, Van Duijnhoven Y, Hanon FX, Brown D, Koopmans M: Viral gastroenteritis outbreaks in Europe, 1995 - 2000. Emerg Infect Dis 2003, 9:90-96.

16. Fankhauser RL, Noel JS, Monroe SS, Ando T, Glas RI: Molecular epidemiology of „Norwalk-like viruses“ in outbreaks of gastroenteritis in the United States. J Infect Dis 1998, 178:1571-I578.

17. De Bruin E, Duizer E, Vennema $H$, Koopmans MP: Diagnosis of Norovirus outbreaks by commercial ELISA or RT-PCR. J Virol Methods 2006, 137:259-264.

18. Okitsu-Negishi S, Okame M, Shimizu Y, Phan TG, Tomaru T, Kamijo S, Sato T, Yagyu F, Müller WEG, Ushijima H: Detection of Norovirus antigens recombinant virus-like particles and stool samples by a commercial Norovirus enzyme-linked immunosorbent assay kit. J Clin Microbiol 2006, 44(I0):3784-3786.

19. Duizer E, Pielaat A, Vennema H, Kroneman A, Koopmans M: Probabilities in norovirus outbreak diagnosis. J Clin Virol 2007, 40:38-42.

20. Rabenau HF, Stürmer M, Buxbaum S, Walczok A, Preiser W, Doerr HW: Laboratory diagnosis of norovirus: which method is the best? Intervirology 2003, 46:232-238.

21. Rockx B, De Wit M, Vennema H, Vinjé J, De Bruin E, Van Duynhoven Y, Koopmans M: Natural history of human calicivirus infection: a prospective cohort study. Clin Infect Dis 2002, 35:246-253.

22. Moreno-Espinosa S, Farkas T, Jiang $X$ : Human caliciviruses and pediatric gastroenteritis. Semin Pediatr Infect Dis 2004, 15:237-245.

23. Kaplan JE, Feldman R, Campbell DS, Lookabaugh C, Gary GW: The frequency of a Norwalk-like pattern of illness in outbreaks of acute gastroenteritis. Am J Public Health 1982, 72:1329-I332.

24. Turcios-Ruiz RM, Axelrod P, St John K, Bullitt E, Donahue J, Robinson $N$, Friss HE: Outbreak of necrotizing enterocolitis caused by norovirus in a neonatal intensive care unit. J Pediatr 2008, 153(3):339-344.

25. Huang PWT, Farkas T, Zhong WM, Thornton S, Morrow AL, Xi J: Norovirus and histo-blood group antigens: Demonstration of a wide spectrum of strain specificities and classification of two major binding groups among multiple binding patterns. J Virol 2005, 79:6714-6722.

26. Phan TG, Kaneshi K, Ueda Y, Nakaya S, Nishimura S, Yamamoto A, Sugita K, Takanashi S, Okitsu S, Ushijima H: Genetic heterogeneity, evolution and recombination in Noroviruses. J Med Virol 2007, 79: $1388-1400$.

27. Karst SM, Wobus CE, Lay M, Davidson J, Virgin HW: STATIdependent innate immunity to a Norwalk-like virus. Science 2003, 299:1575-1578.

28. Prüfung und Deklaration der Wirksamkeit von Desinfektionsmitteln gegen Viren. Bundesgesundheitsbl-GesundheitsforschGesundheitsschutz 2004, 47:62-66.

29. Kramer A, Galabov AS, Sattar SA, Döhner L, Pivert A, Payan C, Wolff $\mathrm{MH}$, Yilmaz A, Steinmann J: Virucidal activity of a new hand dis- 
infectant with reduced ethanol content: comparison with other alcohol-based formulations. J Hosp Infect 2006, 62:98-106.

30. Lopman A, Reacher MH, Vipond IB, Hill D, Perry C, Halladay T, Brown DW, Edmunds W], Sarangi J: Epidemiology and cost of nosocomial gastroenteritis, Avon, England, 2002 - 2003. Emerg Infect Dis 2004, 10:1827-1834.

Publish with Bio Med Central and every scientist can read your work free of charge

"BioMed Central will be the most significant development for disseminating the results of biomedical research in our lifetime. " Sir Paul Nurse, Cancer Research UK

Your research papers will be:

- available free of charge to the entire biomedical community

- peer reviewed and published immediately upon acceptance

- cited in PubMed and archived on PubMed Central

- yours - you keep the copyright

Submit your manuscript here:

http://www.biomedcentral.com/info/publishing_adv.asp 